\title{
Protective effect and mechanism of microRNA-146a on ankle fracture
}

\author{
HAIJUN MAO and GUANGYUE XU \\ Department of Orthopedics, The Affiliated Drum Tower Hospital of Nanjing University Medical School, \\ Nanjing, Jiangsu 210008, P.R. China
}

Received August 13, 2018; Accepted January 10, 2020

DOI: $10.3892 /$ etm.2020.9131

\begin{abstract}
The present study investigated the expression and role of microRNA-146a (miR-146a) on ankle fracture, and explored the underlying mechanism. miR-146a levels in the blood of patients with ankle fracture was measured using reverse transcription-quantitative PCR (RT-qPCR). Expression of pro-inflammatory factors in the peripheral blood of ankle fracture patients was also detected using ELISA. Oxidative stress biomarkers including malondialdehyde (MDA), superoxide dismutase (SOD) and catalase (CAT) were additionally investigated. The role of miR-146a in ankle fracture was investigated in vitro where MG-63 cells were transfected with miR-146a mimic or miR-146a inhibitor for $2 \mathrm{~h}$, then treated with $1 \mu \mathrm{g} / \mathrm{ml}$ bradykinin for $24 \mathrm{~h}$. An MTT assay was then performed to assess cell viability and pro-inflammatory factors were detected via RT-qPCR and western blot analysis. Finally, activation of the TNF receptor associated factor 6 (TRAF6)/NF- $\kappa \mathrm{B}$ pathway was determined via western blotting and RT-qPCR. The results demonstrated that miR-146a was significantly downregulated in the blood of patients with ankle fracture. The protein levels of tumor necrosis factor (TNF- $\alpha$ ), interleukin (IL)-1 $\beta$ and IL-6 were significantly upregulated in patients with ankle fracture. In addition, MDA content significantly increased, and SOD and CAT activity significantly decreased in patients with ankle fracture. In vitro experiments demonstrated that miR-146a overexpression significantly enhanced cell viability. miR-146a mimic suppressed BK-induced upregulation of TNF- $\alpha$, IL-1 $\beta$, IL- 6 and MDA, and increased SOD and CAT activity. Finally, miR-146a mimic inhibited activation of the TRAF6/NF- $\kappa$ B pathway whilst miR-146a inhibitor had the opposite effect. In conclusion, miR-146a may be a potential therapeutic target for
\end{abstract}

Correspondence to: Dr Guangyue Xu, Department of Orthopedics, The Affiliated Drum Tower Hospital of Nanjing University Medical School, 321 Zhongshan Road, Nanjing, Jiangsu 210008, P.R. China E-mail: xugy0813@163.com

Key words: ankle fracture, microRNA-146a, inflammatory response, oxidative stress the treatment of ankle fracture by inhibiting the inflammatory response and attenuating oxidative stress.

\section{Introduction}

Ankle fractures, especially in children, are one of the most common injuries of the bone, with an incidence rate of 187 per 100,000 people $(1,2)$. Delayed diagnosis or treatment of ankle fractures can lead to deformities and disability (3). Therefore, timely diagnosis and effective treatment of fractures are essential for relieving pain and fracture healing. Bone formation is a balanced process between osteoblast and osteoclast activity (4). Following fracture, the expression of pro-inflammatory cytokines, including tumor necrosis factor (TNF)- $\alpha$ and interleukin (IL)-1 $\beta$, are positively correlated with the number of osteoclasts whilst a large number of osteoblasts are required during fracture healing (5). Therefore, the inflammatory response serves an important role in the pathogenesis of ankle fractures whilst oxidative stress has also been implicated in affecting fractures (6).

MicroRNAs (miRNAs or miRs) are a class of small non-coding single stranded RNA that negatively regulates gene expression by binding to the 3'untranslated region (UTR) of multiple target mRNAs (7). miRNAs are involved in various pathophysiological processes, such as the immune response, inflammatory response and oxidative stress (8-10). During fracture, miRNA levels in bone tissue are significantly altered, which may be associated with the fracture healing process affecting osteoblasts and bone growth factors (11). miRNAs serve important roles in fracture healing (11-13); however, the underlying molecular mechanisms have not been fully elucidated.

miR-146a is involved in the development and progression of several diseases, including cancer, arthritis, coronary heart disease and diseases of the nervous system (14-18). Studies have also revealed the important roles of miR-146a in the regulation of inflammation and oxidative stress $(19,20)$. To the best of our knowledge, the expression and functional role of miR-146a in ankle fractures has yet to be fully determined.

The aim of the present study was to investigate the expression and role of miR-146a in the development of ankle fractures and to determine the associated underlying molecular mechanism. 


\section{Materials and methods}

Clinical samples. A total of 60 patients with ankle fracture (12-53 years old; sex ratio, 1:1) presenting at the Affiliated Drum Tower Hospital of Nanjing University Medical School from June 2016 to June 2017 were included in the current study. Peripheral blood samples ( $2 \mathrm{ml}$ per individual) were collected from each patient and 60 healthy volunteers (11-55 years old; sex ratio, 1:1) during the same time period. Each patient provided informed consent and the present study was approved by the Ethics Committee of the Affiliated Drum Tower Hospital of Nanjing University Medical School.

Cell culture and treatment. Human osteoblastic osteosarcoma cell line MG-63 was obtained from the American Type Culture Collection (cat. no. CRL-1427). Cells were cultured in DMEM (Gibco; Thermo Fisher Scientific, Inc.) containing 10\% fetal bovine serum (Gibco; Thermo Fisher Scientific, Inc.) and $1 \%$ penicillin/streptomycin solution (Gibco; Thermo Fisher Scientific, Inc.), then incubated at $37^{\circ} \mathrm{C}$ with $5 \% \mathrm{CO}_{2}$. The cells were passaged every 2-3 days. MG-63 cells were then treated with bradykinin (BK, $1 \mu \mathrm{g} / \mathrm{ml}$; Sigma-Aldrich, Merck KGaA) for $24 \mathrm{~h}$ to establish an in vitro model of ankle fracture

Cell transfection. MG-63 cells were seeded into 6-well plates $\left(1 \times 10^{6}\right.$ cells per well) and cultured at $37^{\circ} \mathrm{C}$ for $24 \mathrm{~h}$. Then $50 \mathrm{nM}$ miR-146a mimic (sense 5'-UGAGAACUGAAUUCCAUG GGUU-3' and antisense 5'-CCCAUGGAAUUCAGUUCU CAUU-3'; Shanghai GenePharma Co., Ltd.), $50 \mathrm{nM}$ mimic control (sense 5'-UUCUCCGAACGUGUCACGUTT-3' and antisense 5'-ACGUGACACGUUCGGAGAATT-3'; Shanghai GenePharma Co., Ltd.), $50 \mathrm{nM}$ miR-146a inhibitor (5'-UGA GAACUGAAUUCCAUGGGUU-3'; Shanghai GenePharma Co., Ltd.) or $50 \mathrm{nM}$ inhibitor control (5'-CAGUACUUU UGUGUAGUACAA-3'; Shanghai GenePharma Co., Ltd.) was transfected into MG-63 cells using Lipofectamine ${ }^{\circledR}$ 2000 reagent (Invitrogen; Thermo Fisher Scientific, Inc.) following the manufacturer's protocol. Transfection efficiency was measured after $24 \mathrm{~h}$. MG-63 cells were pre-transfected with miR-146a mimic, mimic control, miR-146a inhibitor or inhibitor control for $2 \mathrm{~h}$ and then treated with $1 \mu \mathrm{g} / \mathrm{ml} \mathrm{BK}$ at $37^{\circ} \mathrm{C}$ for $24 \mathrm{~h}$, as previously described (21). Subsequently, the cells were subjected to following experiments.

Cell viability assay. Cell viability was determined using an MTT assay. Following transfections and BK treatment, $20 \mu 1$ MTT solution $(5 \mathrm{mg} / \mathrm{ml})$ was added to each well and cells were further incubated for $4 \mathrm{~h}$ at $37^{\circ} \mathrm{C}$. To assess cell viability, absorbance at $490 \mathrm{~nm}$ was measured using a microplate reader (Bio-Rad Laboratories, Inc.).

ELISA. TNF- $\alpha$, IL-1 $\beta$ and IL-6 levels were measured using ELISA. Peripheral blood was collected from patients with or without ankle fracture, after which the serum was isolated via centrifugation at $3,000 \times \mathrm{g}$ at $4^{\circ} \mathrm{C}$ for $15 \mathrm{~min}$. Levels of TNF- $\alpha$ (cat. no. PT518; Beyotime Institute of Biotechnology), IL-1 $\beta$ (cat. no. PI305; Beyotime Institute of Biotechnology) and IL-6 (cat. no. PI330; Beyotime Institute of Biotechnology) in serum were detected using ELISA kits according to the manufacturer's protocol.
Measurement of oxidative stress-associated indicators. Peripheral blood from patients with or without ankle fracture was collected and the serum was isolated by centrifugation at $3,000 \mathrm{x} \mathrm{g}$ at $4^{\circ} \mathrm{C}$ for $15 \mathrm{~min}$. For in vitro experiments, MG-63 cells $\left(5 \times 10^{4}\right.$ cells per well) were plated into six-well plates and transfected with miR-146a mimic, mimic control, miR-146a inhibitor or inhibitor control for $2 \mathrm{~h}$, after which cells were treated with $1 \mu \mathrm{g} / \mathrm{ml} \mathrm{BK}$ at $37^{\circ} \mathrm{C}$ for $24 \mathrm{~h}$. Subsequently, MG-63 cells were harvested and the supernatants collected via centrifugation at $1,600 \mathrm{xg}$ for $10 \mathrm{~min}$ at $4^{\circ} \mathrm{C}$. malondialdehyde (MDA; cat. no. S0131M; Beyotime Institute of Biotechnology) levels, and superoxide dismutase (SOD; cat. no. S0086; Beyotime Institute of Biotechnology) and catalase (CAT; cat. no. S0082; Beyotime Institute of Biotechnology) enzymatic activities were determined in the blood of patients with or without ankle fracture. MG-63 cells were detected using the appropriate kits as per the manufacturer's protocol. The enzyme activity of cells was presented as units/mg of protein as previously described in the literature (22).

Western blot analysis. Protein levels of TNF receptor associated factor 6 (TRAF6), phosphorylated (p)-NF- $\mathrm{BB}$ (p-p65), p- 65 , TNF- $\alpha$, IL-1 $\beta$, IL- 6 or $\beta$-actin in MG63 cells were determined via western blot analysis. Total protein from cells was extracted using lysis buffer (Cell Signaling Technology, Inc.). A bicinchoninic acid protein assay (Thermo Fisher Scientific, Inc.) was used to determine the concentration of protein samples. An equal quantity of protein (30 $\mu \mathrm{g}$ per lane) were then separated by SDS-PAGE on a $12 \%$ gel, transferred onto polyvinylidene difluoride membranes then blocked with $5 \%$ non-fat milk at room temperature for $2 \mathrm{~h}$. Subsequently, the membranes were incubated with primary antibodies against TRAF6 (cat. no. 8028), p-NFKB p65 (cat. no. 3033), p65 (cat. no. 8242), TNF- $\alpha$ (cat. no. 3707), IL-1 $\beta$ (cat. no. 12703), IL-6 (cat. no. 12153) or $\beta$-actin (cat. no. 4970; all 1:1,000; all Cell Signaling Technology, Inc.) overnight at $4^{\circ} \mathrm{C}$. Membranes were then incubated with an anti-rabbit immunoglobulin G, horseradish peroxidase-linked antibody (1:5,000; cat. no. 7074; Cell Signaling Technology, Inc.) at room temperature for $2 \mathrm{~h}$. Finally, protein bands were visualized using the enhanced chemiluminescence detection system (Super Signal West Dura Extended Duration Substrate; Pierce Chemical; Thermo Fisher Scientific, Inc.) and quantified with Image J software (version 1.48u; National Institutes of Health).

Reverse transcription-quantitative PCR (RT-qPCR). TRIzol ${ }^{\circledR}$ regent (Invitrogen; Thermo Fisher Scientific, Inc.) was used to extract RNA from blood samples and cells. PrimeScript reverse transcription reagent kit (Takara Biotechnology Co., Ltd.) was used to synthesize cDNAs as per the manufacturer's protocol. The temperature protocol for this step was as follows: $70^{\circ} \mathrm{C}$ for $5 \mathrm{~min}, 37^{\circ} \mathrm{C}$ for $5 \mathrm{~min}$ and $42^{\circ} \mathrm{C}$ for $1 \mathrm{~h}$. qPCR was subsequently performed using a TaqMan Universal PCR Master Mix kit (Thermo Fisher Scientific, Inc.) according to the manufacturer's protocol. The following primer sequences were used: miR-146a forward, 5'-GCGAGGTCAAGTCACTAG TGGT-3' and reverse, 5'-CGAGAAGCTTGCATCACCAGA GAACG-3'; TRAF6 forward, 5'-GCAGTGAAAGATGAC AGCGTGA-3' and reverse, 5'-TCCCGTAAAGCCATCAAG CA-3'; TNF- $\alpha$ forward, 5'-GAACTGGCAGAAGAGGCA 

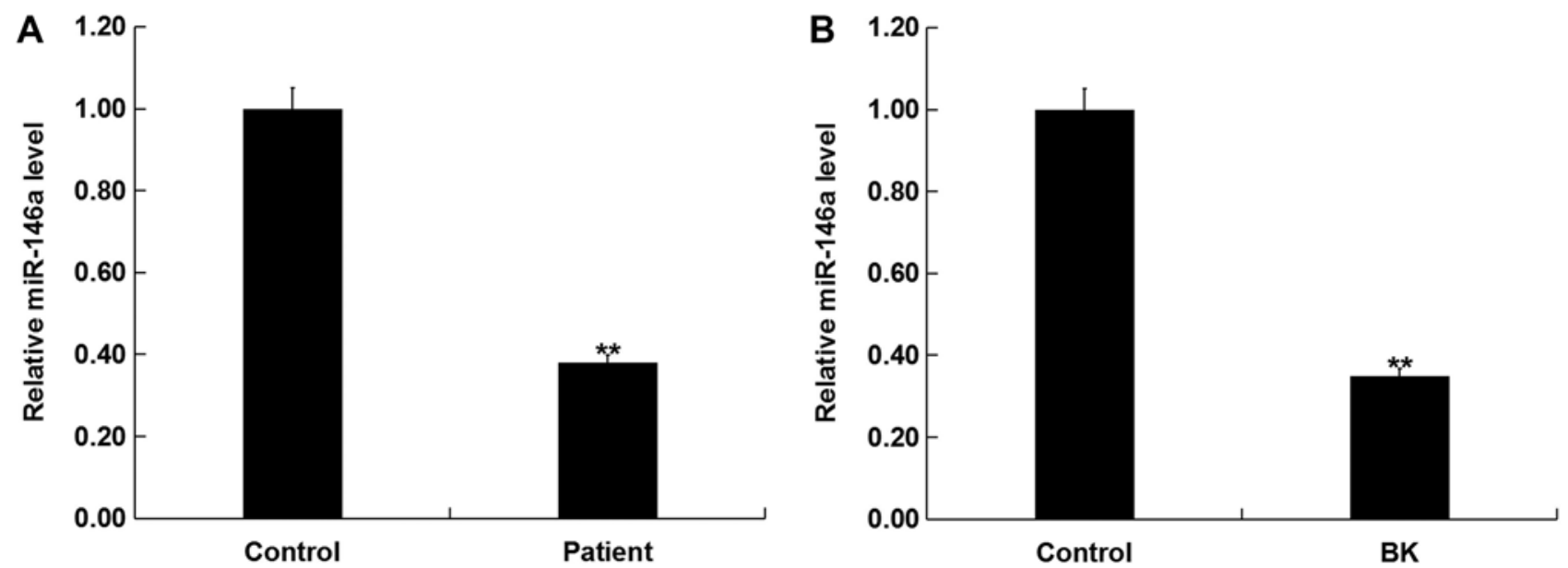

Figure 1. miR-146a expression was decreased in patients with ankle fracture and following BK treatment. (A) miR-146a levels in the blood samples of patients with and without ankle fracture were detected via RT-qPCR. (B) MG-63 cells were stimulated with $1 \mu \mathrm{g} / \mathrm{ml} \mathrm{BK}$ for $24 \mathrm{~h}$, after which miR-146a levels were detected via RT-qPCR. ${ }^{* *} \mathrm{P}<0.01$ vs. control. miR, microRNA; BK, bradykinin; RT-qPCR, reverse transcription-quantitative PCR.

CT-3' and reverse, 5'-GGTCTGGGCCATAGAACTGA-3'; IL-1 $\beta$ forward, 5'-TGTGAAATGCCACCTTTTGA-3' and reverse, 5'-TGAGTGATACTGCCTGCCTG-3'; IL-6 forward, 5'-CCGGAGAGGAGACTTCACAG-3' and reverse, 5'-CAG AATTGCCATTGCACA-3'; GAPDH forward, 5'-GGCATT GCTCTCAATGACAA-3' and reverse, 5'-TGTGAGGGAGAT GCTCAGTG-3' and U6 forward, 5'-CTCGCTTCGGCAGCA CA-3' and reverse, 5'-AACGCTTCACGAATTTGCGT-3'. U6 or GAPDH was used as internal reference genes. mRNA relative expression was quantified using the $2^{-\Delta \Delta \mathrm{Cq}}$ method (23).

Statistical analysis. All data were analyzed using SPSS version 18.0 (SPSS, Inc.) and data were presented as the mean \pm standard deviation. Differences between two groups were determined using a Student's t test and differences between multiple groups were determined using one-way ANOVA followed by Student-Neuman-Keuls post hoc test. $\mathrm{P}<0.05$ was considered to indicate a statistically significant difference.

\section{Results}

miR-146a is decreased in patients with ankle fracture. Levels of miR-146a in the blood of patients with or without ankle fracture were determined via RT-qPCR. Compared with the healthy control, levels of miR-146a were significantly decreased in patients with ankle fracture (Fig. 1A). Furthermore, MG-63 cells stimulated with $\mathrm{BK}$ to establish an in vitro model of ankle fracture demonstrated significantly decreased miR-146a levels (Fig. 1B).

Inflammatory response and oxidative stress increases in patients with ankle fracture. ELISA was used to determine the levels of pro-inflammatory factors (TNF- $\alpha$, IL- $1 \beta$ and IL-6) in the blood of patients with ankle fracture. The results determined that, compared with the healthy controls, TNF- $\alpha$, IL-1 $\beta$ and IL- 6 levels significantly increased in patients with ankle fracture (Fig. 2A-C).

In addition, MDA levels significantly increased, whilst SOD and CAT activities significantly decreased in patients with ankle fracture compared with the healthy controls (Fig. 2D-F).
These results indicated that there was an enhanced inflammatory response and increased oxidative stress in patients with ankle fracture.

miR-146a increases cell viability following BK treatment in vitro. To further elucidate the role of miR-146a in ankle fracture, MG-63 cells were transfected with miR-146a mimic, mimic control, miR-146a inhibitor or inhibitor control, after which cells were treated with $1 \mu \mathrm{g} / \mathrm{ml} \mathrm{BK}$ for $24 \mathrm{~h}$. Transfection efficiency was determined via RT-qPCR $24 \mathrm{~h}$ post cell transfection. The results demonstrated that compared with the control group, miR-146a mimic significantly enhanced miR-146a expression, whilst miR-146a inhibitor significantly decreased the level of miR-146a (Fig. 3A and B). Additionally cell viability was significantly decreased in BK-treated MG-63 cells compared with the control group. miR-146a mimic significantly promoted cell viability following BK treatment (Fig. 3C), while miR-146a inhibitor significantly decreased cell viability (Fig. 3D).

miR-146a decreases pro-inflammatory factor expression following $B K$ treatment in vitro. Levels of pro-inflammatory factors (TNF- $\alpha$, IL-1 $\beta$ and IL-6) in MG-63 cells were determined via RT-qPCR and western blot analysis. The results revealed that BK treatment significantly increased TNF- $\alpha$, IL-1 $\beta$ and IL-6 mRNA and protein levels (Fig. 4A-D). By contrast, miR-146a mimic treatment decreased pro-inflammatory factors following BK treatment (Fig. 4A-D). miR-146a inhibitor significantly increased TNF- $\alpha$, IL-1 $\beta$ and IL- 6 levels compared with the controls and BK treatment group (Fig. 4E-H).

miR-146a attenuates oxidative stress following BK treatment in vitro. BK treatment significantly increased MDA levels, while the activities of SOD and CAT decreased compared with the control (Fig. 5A-C). Additionally, miR-146a mimic significantly decreased MDA levels, and increased SOD and CAT activities following BK treatment (Fig. 5A-C). miR-146a inhibitor significantly increased MDA levels, while the activities of SOD and CAT decreased compared with the control and BK treatment groups (Fig. 5D-F). 

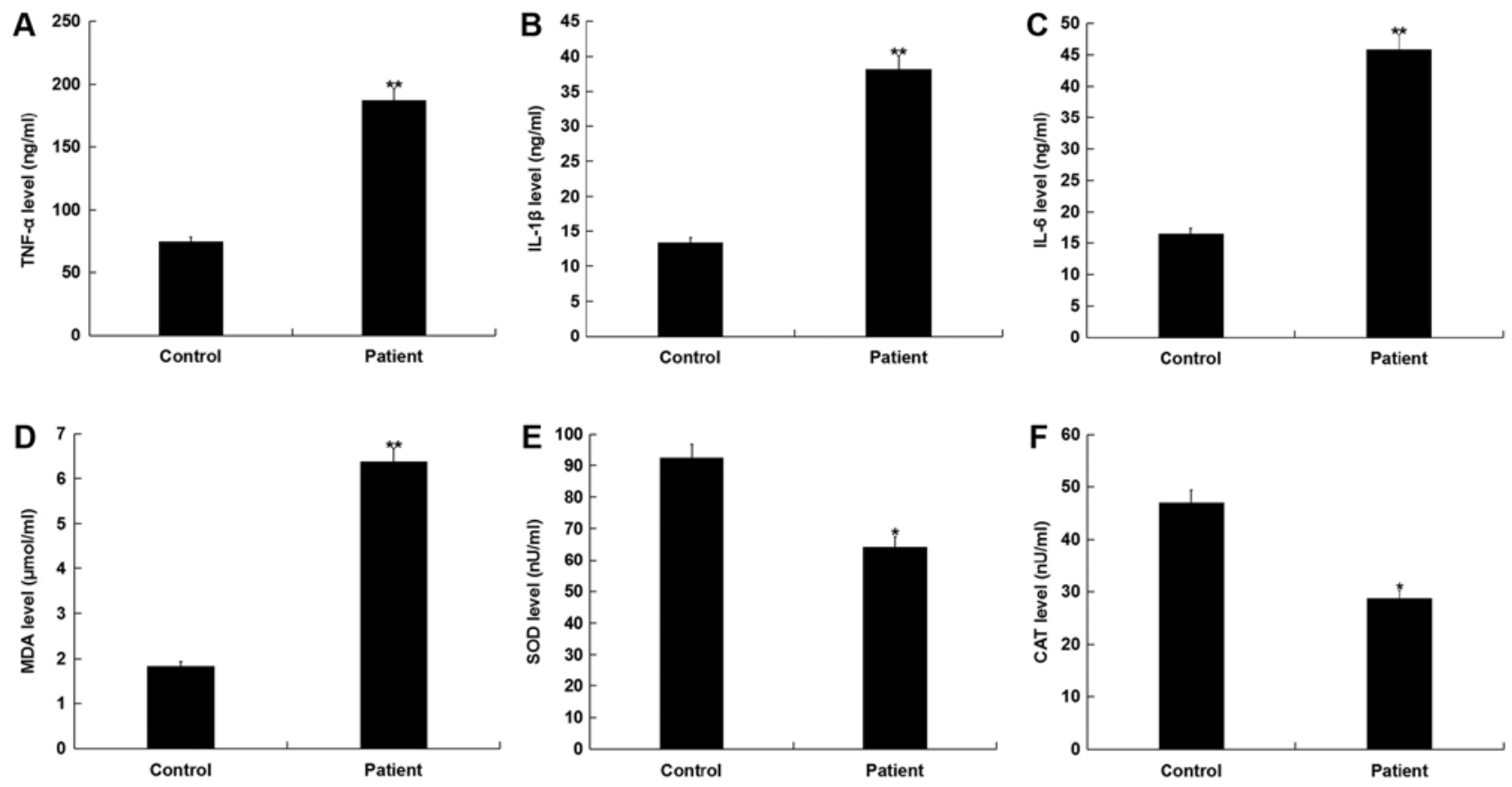

Figure 2. Inflammatory response and oxidative stress levels were increased in patients with ankle fracture. (A) TNF- $\alpha$, (B) IL-1 $\beta$ and (C) IL-6 levels in patients with or without ankle fracture were detected via ELISA. (D) MDA levels, (E) SOD and (F) CAT activities in patients with or without fractured ankle were also determined. ${ }^{*} \mathrm{P}<0.05$ and ${ }^{* *} \mathrm{P}<0.01$ vs. control. TNF- $\alpha$, tumor necrosis factor- $\alpha$; IL, interleukin; MDA, malondialdehyde; SOD, superoxide dismutase; CAT, catalase.

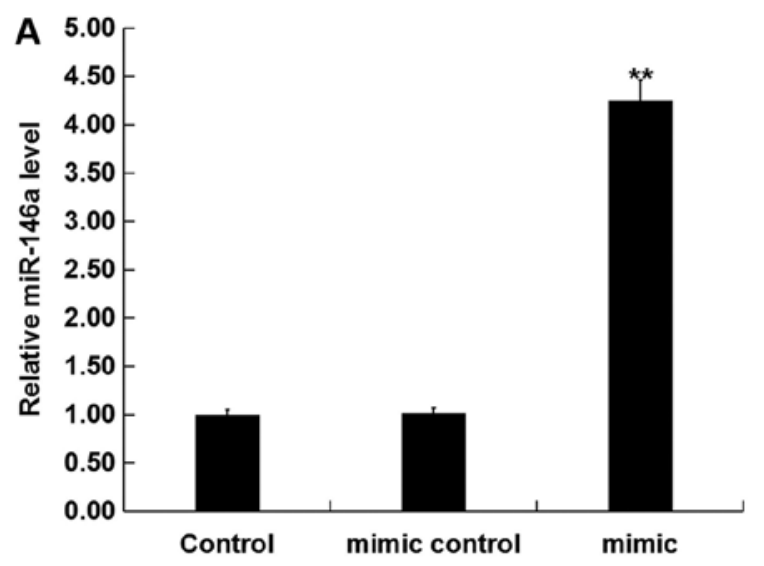

B
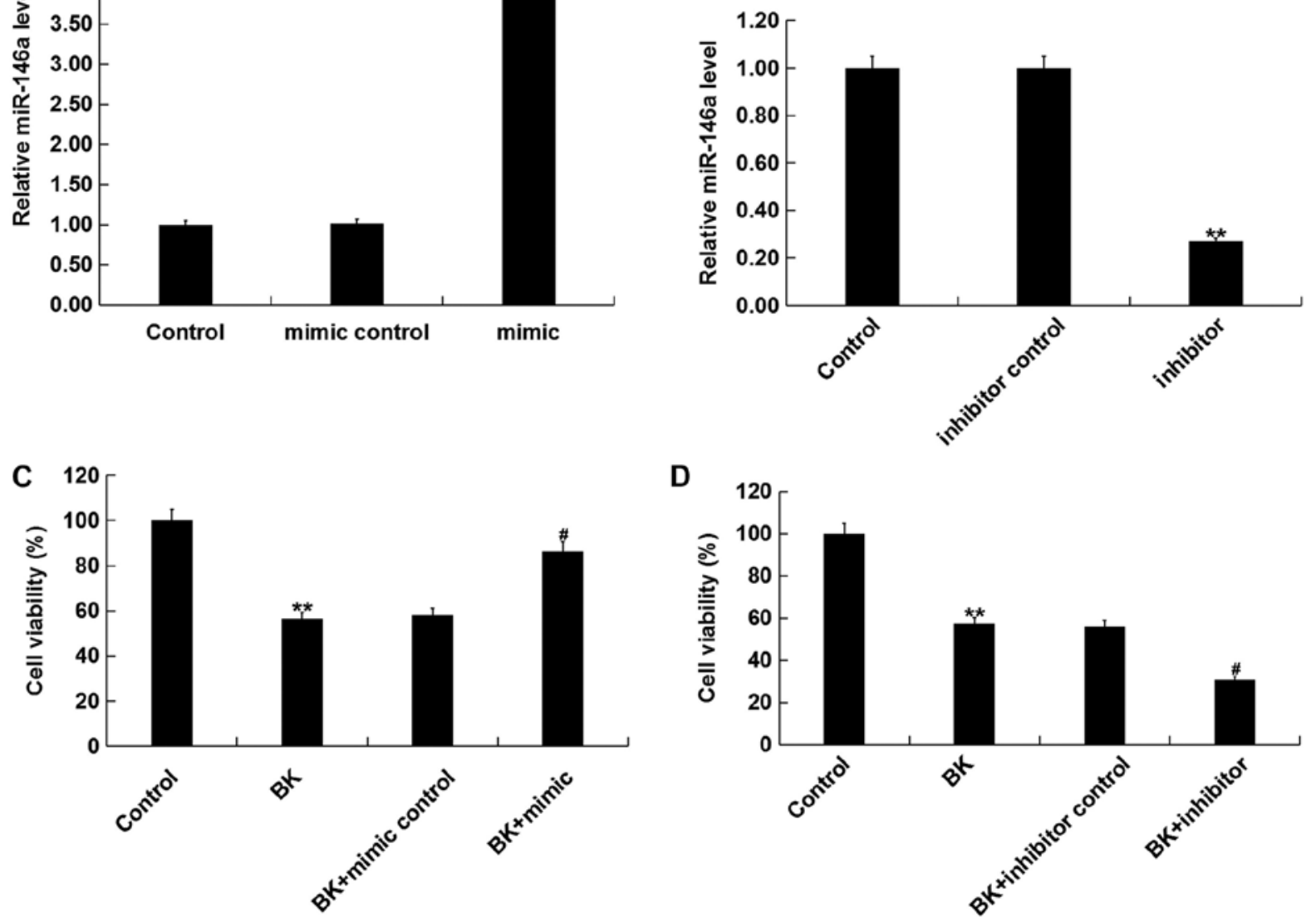

Figure 3. miR-146a increased cell viability following BK treatment in vitro. (A) miR-146a-mimic increased miR-146a levels and (B) miR-146a inhibitor reduced miR-146a levels. (C) miR-146a-mimic increased cell viability and (D) inhibition of miR-146a reduced cell viability following BK treatment. ${ }^{* *} \mathrm{P}<0.01$ vs. control; ${ }^{\#} \mathrm{P}<0.05$ vs. BK only treatment group. miR, microRNA; BK, bradykinin. 

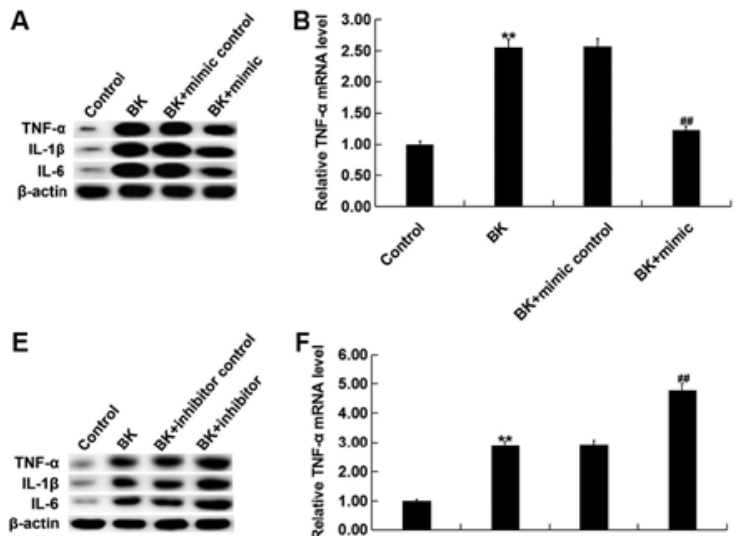
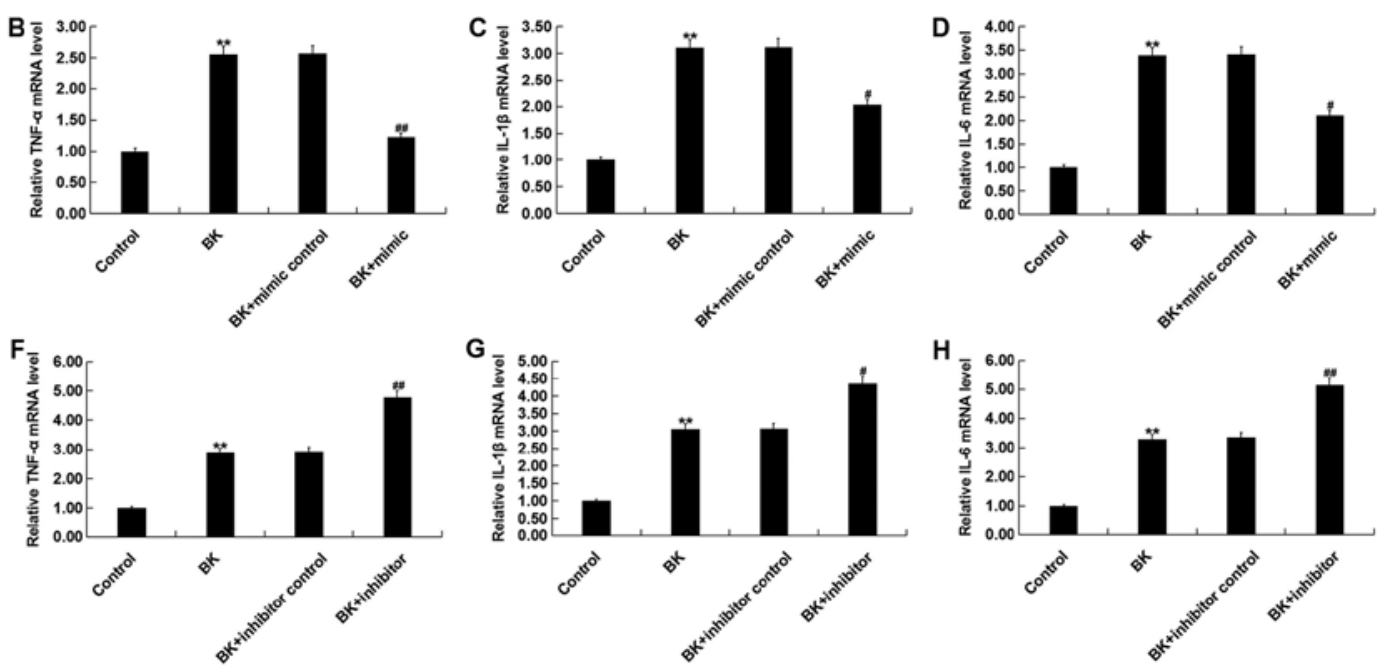

Figure 4. miR-146a reduced the inflammatory response following BK treatment in vitro. (A) Representative blots of cytokine protein expression following miR-146a overexpression and BK treatment. (B) miR-146a-mimic reduced TNF- $\alpha$, (C) IL-1 $\beta$ and (D) IL-6 mRNA levels following BK treatment, as detected via RT-qPCR. (E) Representative blots of cytokine protein expression following miR-146a inhibition and BK treatment. (F) Inhibition of miR-146a increased TNF- $\alpha$, (G) IL-1 $\beta$ and (H) IL-6 mRNA levels following BK treatment, as detected via RT-qPCR. ${ }^{* *} \mathrm{P}<0.01$ vs. control; ${ }^{*} \mathrm{P}<0.05$ and ${ }^{* \#} \mathrm{P}<0.01$ vs. BK only treatment group. miR, microRNA; BK, bradykinin; TNF- $\alpha$, tumor necrosis factor- $\alpha$; IL, interleukin; RT-qPCR, reverse transcription-quantitative PCR.
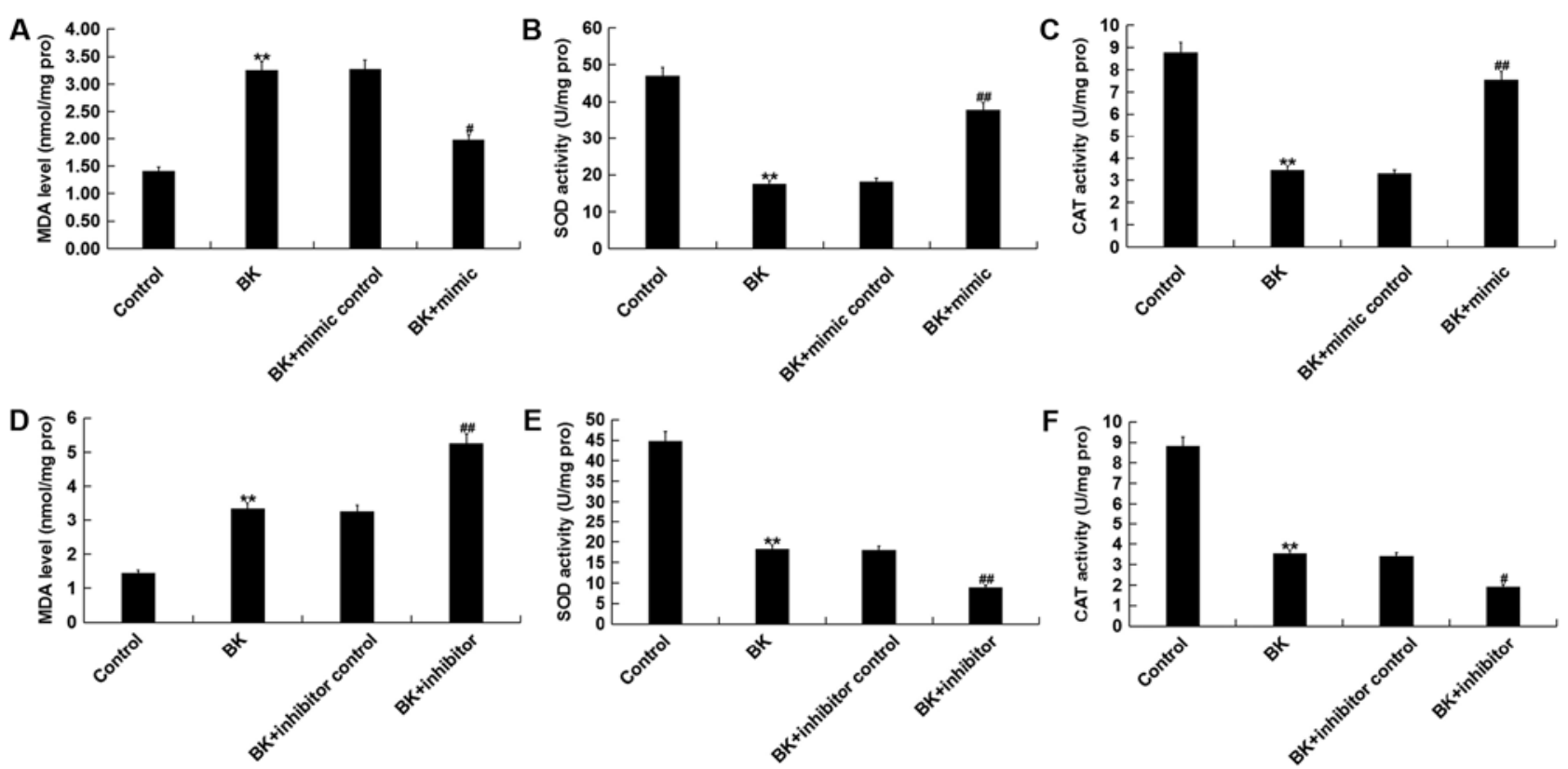

Figure 5. miR-146a attenuated oxidative stress following BK treatment in vitro. (A) The effect of miR-146a overexpression on MDA levels. (B) SOD and (C) CAT activity following miR-146a overexpression and BK treatment. (D) The effect of inhibition of miR-146a on MDA levels. (E) SOD and (F) CAT activity following miR-146a inhibition and BK treatment. ${ }^{* *} \mathrm{P}<0.01$ vs. control; ${ }^{~} \mathrm{P}<0.05$ and ${ }^{\# \#} \mathrm{P}<0.01$ vs. BK only treatment group. miR, microRNA; BK, bradykinin; MDA, malondialdehyde; SOD, superoxide dismutase; CAT, catalase.

Effect of miR-146a on the TRAF6/NF- $\mathrm{BB}$ pathway following BK treatment in vitro. Previous studies have identified the inhibitory effect of miR-146a on the TRAF6/NF- $\mathrm{B}$ pathway $(14,20,24)$. Therefore, the molecular mechanism of miR-146a in ankle fracture and whether the TRAF6/NF- $\mathrm{KB}$ pathway was involved, was assessed in the present study. The results demonstrated that TRAF6 protein and mRNA levels, and $\mathrm{p}-\mathrm{NF}-\kappa \mathrm{B}$ p-p- 65 protein levels were increased compared with the control group following BK treatment (Fig. 6). miR-146a mimic significantly decreased TRAF6 protein and mRNA levels, and p-p-65 protein level following BK treatment (Fig. 6A and B). miR-146a inhibitor significantly increased TRAF6 protein and mRNA levels, and $\mathrm{p}-\mathrm{NF}-\kappa \mathrm{B}$ p-p-65 protein level compared with the control and BK treatment (Fig. 6C and D). No significant changes were obtained in the protein expression of p- 65 .

\section{Discussion}

Fractures, particularly affecting the ankles, are common. Ankle fractures can have serious consequences without timely diagnosis and treatment. Therefore, effective treatment strategies are urgently required. In recent years, an increasing number 

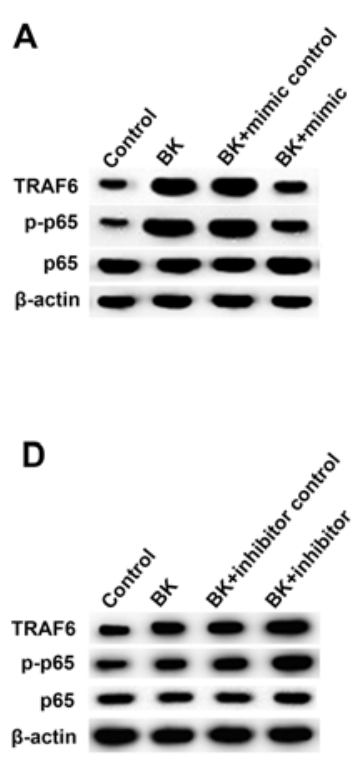

B

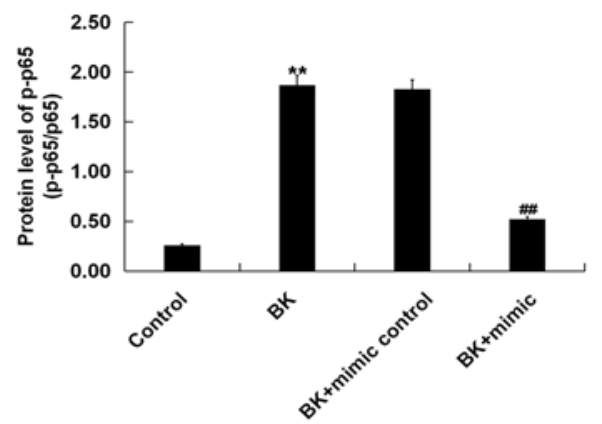

E

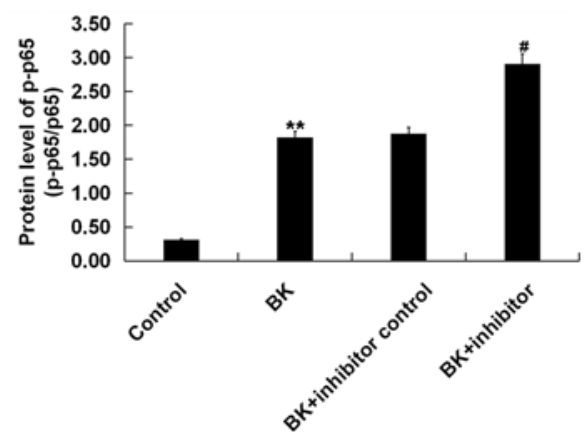

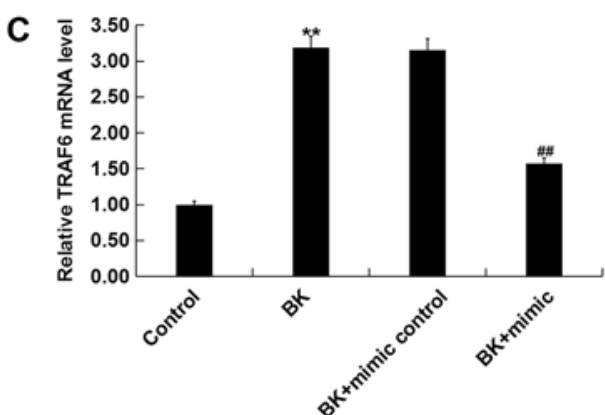

$F$

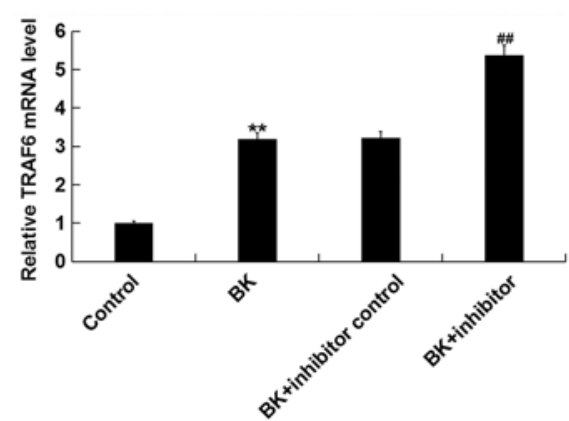

Figure 6. miR-146a inhibited the activation of the TRAF6/NF- $\kappa$ B pathway following BK treatment in vitro. (A) Representative blots for TRAF6 and p-NF- $\kappa$ B p65 following miR-146a overexpression and BK treatment. (B) TRAF6 mRNA expression following miR-146a overexpression and BK treatment, as detected via RT-qPCR. (C) Representative blots for TRAF6 and p-NF- $\kappa$ B p65 following miR-146a inhibition and BK treatment. (D) TRAF6 mRNA expression following miR-146a inhibition and BK treatment, as detected via RT-qPCR. (E) Ratio of p-p65/total-p65 in cells following miR-146a inhibition and BK treatment. (F) TRAF6 mRNA expression in cells following miR-146a inhibition and BK treatment. ${ }^{* *} \mathrm{P}<0.01$ vs. control; ${ }^{*} \mathrm{P}<0.05$, ${ }^{\# \#} \mathrm{P}<0.01$ vs. BK only treatment group. miR, microRNA; TRAF6, TNF receptor associated factor 6; p-NF- $\mathrm{B}$, phosphorylated-NF- $\mathrm{B}$; BK, bradykinin; RT-qPCR, reverse transcription-quantitative PCR.

of studies have demonstrated the important roles of miRNAs in the pathogenesis and development of fractures (25-29). Zou et al (25) identified that miR-124 polymorphism is associated with fracture healing by targeting bone morphogenetic protein 6. Yoshizuka et al (26) reported that miR-222 downregulation accelerated bone healing in rats. Lee et al (27) determined that miR-29b promoted bone healing in a mouse fracture model. In addition, mesenchymal stem cells overexpressing miR-21 accelerated fracture healing in a rat closed femur fracture model (28). A further study demonstrated that miR-92a inhibition enhanced fracture healing by promoting angiogenesis (29). Therefore, miRNAs may provide a novel approach for the treatment of ankle fracture.

The present study investigated the expression and role of miR-146a in the development of fractures. miR-146a is involved in various diseases, such as numerous types of cancer, arthritis, coronary heart disease and Alzheimer's disease, and serves important roles in regulating inflammation and oxidative stress (14-20). In the present study, the level of miR-146a in the blood samples of patients with ankle fracture was lower than those without ankle fracture. For in vitro experiments, MG-63 cells were treated with $1 \mu \mathrm{g} / \mathrm{ml} \mathrm{BK}$ for $24 \mathrm{~h}$ to establish a model of ankle fracture. The results demonstrated that BK treatment significantly decreased the level of miR-146a in cells. These results indicated that miR-146a was significantly decreased during fracture, further suggesting that it might serve an important role in fracture development. To confirm the elevated inflammatory response and oxidative stress during ankle fracture, levels of pro-inflammatory factors, including TNF- $\alpha$, IL-1 $\beta$ and IL- 6 , and bio-markers of oxidative stress, including MDA, SOD and CAT, were determined. The results revealed that the inflammatory response and oxidative stress significantly increased in ankle fracture. miR-146a was then overexpressed or downregulated in MG-63 cells following BK treatment. miR-146a overexpression significantly promoted cell viability and suppressed the BK-induced elevation of the inflammatory response and oxidative stress. By contrast, treatment with the miR-146a inhibitor demonstrated the opposite effect on cell viability, the inflammatory response and oxidative stress. Previous studies have identified the inhibitory effect of miR-146a on the TRAF6/NF- $\kappa$ B pathway $(30,31)$. Therefore, whether the TRAF6/NF- $\mathrm{B}$ pathway was involved in the molecular mechanism of miR-146a on ankle fracture was investigated in the present study. The results demonstrated that miR-146a overexpression markedly inhibited the TRAF6/NF- $\kappa$ B pathway following BK treatment, whilst miR-146a inhibition promoted the TRAF6/NF- $\kappa \mathrm{B}$ pathway.

The present study is preliminary work into the role of miR-146a in ankle fracture; therefore, to make the conclusions more convincing, the correlation between miR-146a expression and clinical characteristics of patients with ankle fracture will be investigated in future.

In conclusion, the clinical results of the present study identified that miR-146a was downregulated during ankle fracture. For in vitro experiments, miR-146a protected against inflammation and oxidative stress and inhibited the TRAF6/NF- $\kappa$ B pathway following establishment of a fracture model. The present results suggested that miR-146a might promote ankle fracture healing and thus, may be a potential therapeutic target for ankle fracture treatment. 


\section{Acknowledgements}

Not applicable.

\section{Funding}

No funding was received.

\section{Availability of data and materials}

The datasets used and/or anlayzed during the current study are available from the corresponding author on reasonable request.

\section{Authors' contributions}

HM contributed to study design, data collection, statistical analysis, data interpretation and manuscript preparation. GX contributed to data collection and statistical analysis. All authors read and approved the final manuscript.

\section{Ethics approval and consent to participate}

Each patient provided informed consent and the current study was approved by the Ethics Committee of the Affiliated Drum Tower Hospital of Nanjing University Medical School.

\section{Patient consent for publication}

Not applicable.

\section{Competing interests}

The authors declare that they have no competing interests.

\section{References}

1. Hedström EM, Svensson O, Bergström U and Michno P Epidemiology of fractures in children and adolescents. Acta Orthop 81: 148-153, 2010.

2. MacIntyre $\mathrm{NJ}$ and Dewan $\mathrm{N}$ : Epidemiology of distal radius fractures and factors predicting risk and prognosis. J Hand Ther 29: 136-145, 2016.

3. Chevalley T, Bonjour JP, van Rietbergen B, Rizzoli R and Ferrari S: Fractures in healthy females followed from childhood to early adulthood are associated with later menarcheal age and with impaired bone microstructure at peak bone mass. J Clin Endocrinol Metab 97: 4174-4181, 2012.

4. He Z, Selvamurugan N, Warshaw J and Partridge NC: Pulsed electromagnetic fields inhibit human osteoclast formation and gene expression via osteoblasts. Bone 106: 194-203, 2017.

5. Huang H,Zhao N,XuX,Xu Y,Li S,Zhang J and Yang P: Dose-specific effects of tumor necrosis factor alpha on osteogenic differentiation of mesenchymal stem cells. Cell Prolif 44: 420-427, 2014.

6. Sheweita SA and Khoshhal KI: Calcium metabolism and oxidative stress in bone fractures: Role of antioxidants. Curr Drug Metab 8: 519-525, 2007.

7. Hammond SM: An overview of microRNAs. Adv Drug Deliv Rev 87: 3-14, 2015.

8. Soifer HS, Rossi JJ and Saetrom P: MicroRNAs in disease and potential therapeutic applications. Mol Ther 15: 2070-2079, 2017.

9. Krol J, Loedige I and Filipowicz W: The widespread regulation of microRNA biogenesis, function and decay. Nat Rev Genet 11: 597-610, 2010.

10. O'Connell RM, Rao DS, Chaudhuri AA and Baltimore D Physiological and pathological roles for microRNAs in the immune system. Nat Rev Immunol 10: 111-122, 2010.
11. Nugent M: MicroRNAs and fracture healing. Calcif Tissue Int 101: 355-361, 2017.

12. He B, Zhang ZK, Liu J, He YX, Tang T, Li J, Guo BS, Lu AP, Zhang BT and Zhang G: Bioinformatics and microarray analysis of miRNAs in aged female mice model implied new molecular mechanisms for impaired fracture healing. Int J Mol Sci 17: E1260, 2016.

13. Waki T, Lee SY, Niikura T, Iwakura T, Dogaki Y, Okumachi E, Oe K, Kuroda R and Kurosaka M: Profiling microRNA expression during fracture healing. BMC Musculoskelet Disord 17: 83, 2016.

14. Tan W, Liao Y, Qiu Y, Liu H, Tan D, Wu T, Tang M, Zhang S and Wang $\mathrm{H}$ : miRNA 146a promotes chemotherapy resistance in lung cancer cells by targeting DNA damage inducible transcript 3 (CHOP). Cancer Lett 428: 55-68, 2018.

15. Li D, Duan M, Feng Y, Geng L, Li X and Zhang W: MiR-146a modulates macrophage polarization in systemic juvenile idiopathic arthritis by targeting INHBA. Mol Immunol 77: 205-212, 2016.

16. Wu ZW, Liu YF, Wang S and Li B: miRNA-146a induces vascular smooth muscle cell apoptosis in a rat model of coronary heart disease via NF-кB pathway. Genet Mol Res 14: 18703-18712, 2015.

17. Zhang B, Wang LL, Ren RJ, Dammer EB, Zhang YF, Huang Y, Chen SD and Wang G: MicroRNA-146a represses LRP2 translation and leads to cell apoptosis in Alzheimer's disease. FEBS Lett 590: 2190-2200, 2016

18. Lukiw WJ, Cui JG, Yuan LY, Bhattacharjee PS, Corkern M, Clement C, Kammerman EM, Ball MJ, Zhao Y, Sullivan PM and Hill JM: Acyclovir or A $\beta 42$ peptides attenuate HSV-1-induced miRNA-146a levels in human primary brain cells. Neuroreport 21: 922-927, 2010.

19. Xie Y, Chu A, Feng Y, Chen L, Shao Y, Luo Q, Deng X, Wu M, Shi X and Chen Y: MicroRNA-146a: A comprehensive indicator of inflammation and oxidative stress status induced in the brain of chronic T2DM rats. Front Pharmacol 9: 478, 2018.

20. Liu L, Wan C, Zhang W, Guan L, Tian G, Zhang F and Ding W: MiR-146a regulates PM1 -induced inflammation via NF- $\kappa B$ signaling pathway in BEAS-2B cells. Environ Toxicol 33: 743-751, 2018.

21. Zhou P, Liu H, Wu Y and Chen D: Propofol promotes ankle fracture healing in children by inhibiting inflammatory response. Med Sci Monit 24: 4379-4385, 2018.

22. Lu W, Kang J, Hu K, Tang S, Zhou X, Yu S, Li Y and Xu L: Angiotensin-(1-7) inhibits inflammation and oxidative stress to relieve lung injury induced by chronic intermittent hypoxia in rats. Braz J Med Biol Res 49: e5431, 2016.

23. Livak KJ and Schmittgen TD: Analysis of relative gene expression data using real-time quantitative PCR and the 2(-Delta Delta C(T)) method. Methods 25: 402-408, 2001.

24. LvF,Huang YZ,Lv WT, Yang L,LiF,Fan J and Sun J: MicroRNA-146a ameliorates inflammation via TRAF6/NF- $\mathrm{BB}$ pathway in intervertebral disc cells. Med Sci Monit 23: 659-664, 2017.

25. Zou L, Zhang G, Liu L, Chen C, Cao X and Cai J: A MicroRNA-124 polymorphism is associated with fracture healing via modulating BMP6 expression. Cell Physiol Biochem 41: 2161-2170, 2017.

26. Yoshizuka M, Nakasa T, Kawanishi Y, Hachisuka S, Furuta T, Miyaki S, Adachi N and Ochi M: Inhibition of microRNA-222 expression accelerates bone healing with enhancement of osteogenesis, chondrogenesis, and angiogenesis in a rat refractory fracture model. J Orthop Sci 21: 852-858, 2016.

27. Lee WY, Li N, Lin S, Wang B, Lan HY and Li G: miRNA-29b improves bone healing in mouse fracture model. Mol Cell Endocrinol 430: 97-107, 2016.

28. Sun Y, Xu L, Huang S, Hou Y, Liu Y, Chan KM, Pan XH and Li G: mir-21 overexpressing mesenchymal stem cells accelerate fracture healing in a rat closed femur fracture model. Biomed Res Int 2015: 412327, 2015.

29. Murata K, Ito H, Yoshitomi H, Yamamoto K, Fukuda A, Yoshikawa J, Furu M, Ishikawa M, Shibuya H and Matsuda S: Inhibition of miR-92a enhances fracture healing via promoting angiogenesis in a model of stabilized fracture in young mice. J Bone Miner Res 29: 316-326, 2014.

30. He X, Zheng Y, Liu S, Shi S, Liu Y, He Y, Zhang C and Zhou X: MiR-146a protects small intestine against ischemia/reperfusion injury by down-regulating TLR4/TRAF6/NF- $\mathrm{BB}$ pathway. J Cell Physiol 233: 2476-2488, 2018.

31. Zhong JH, Li J, Liu CF, Liu N, Bian RX, Zhao SM, Yan SY and Zhang YB: Effects of microRNA-146a on the proliferation and apoptosis of human osteoarthritis chondrocytes by targeting TRAF6 through the NF- $\mathrm{B}$ signalling pathway. Biosci Rep 37: BSR20160578, 2017.

This work is licensed under a Creative Commons Attribution-NonCommercial-NoDerivatives 4.0 International (CC BY-NC-ND 4.0) License. 